May 2004 • NREL/TP-500-35889

\title{
Wind-Battery-Hydrogen Integration Study
}

\section{Lee Jay Fingersh}

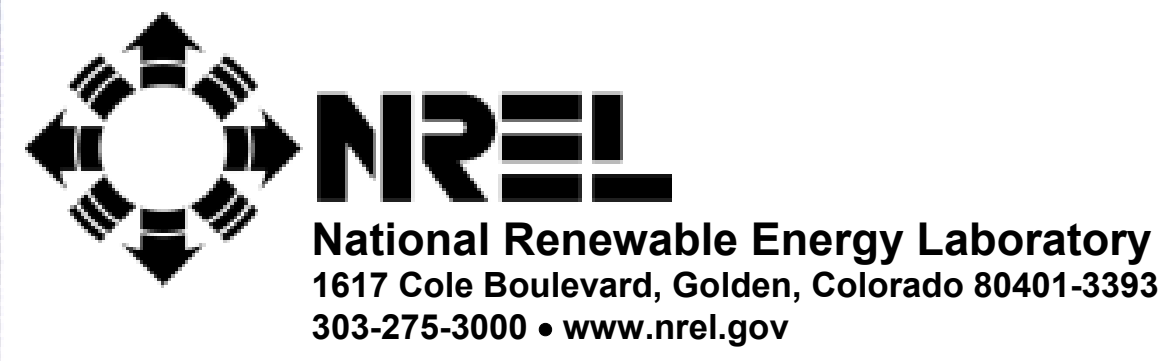

Operated for the U.S. Department of Energy

Office of Energy Efficiency and Renewable Energy

by Midwest Research Institute • Battelle

Contract No. DE-AC36-99-G010337 


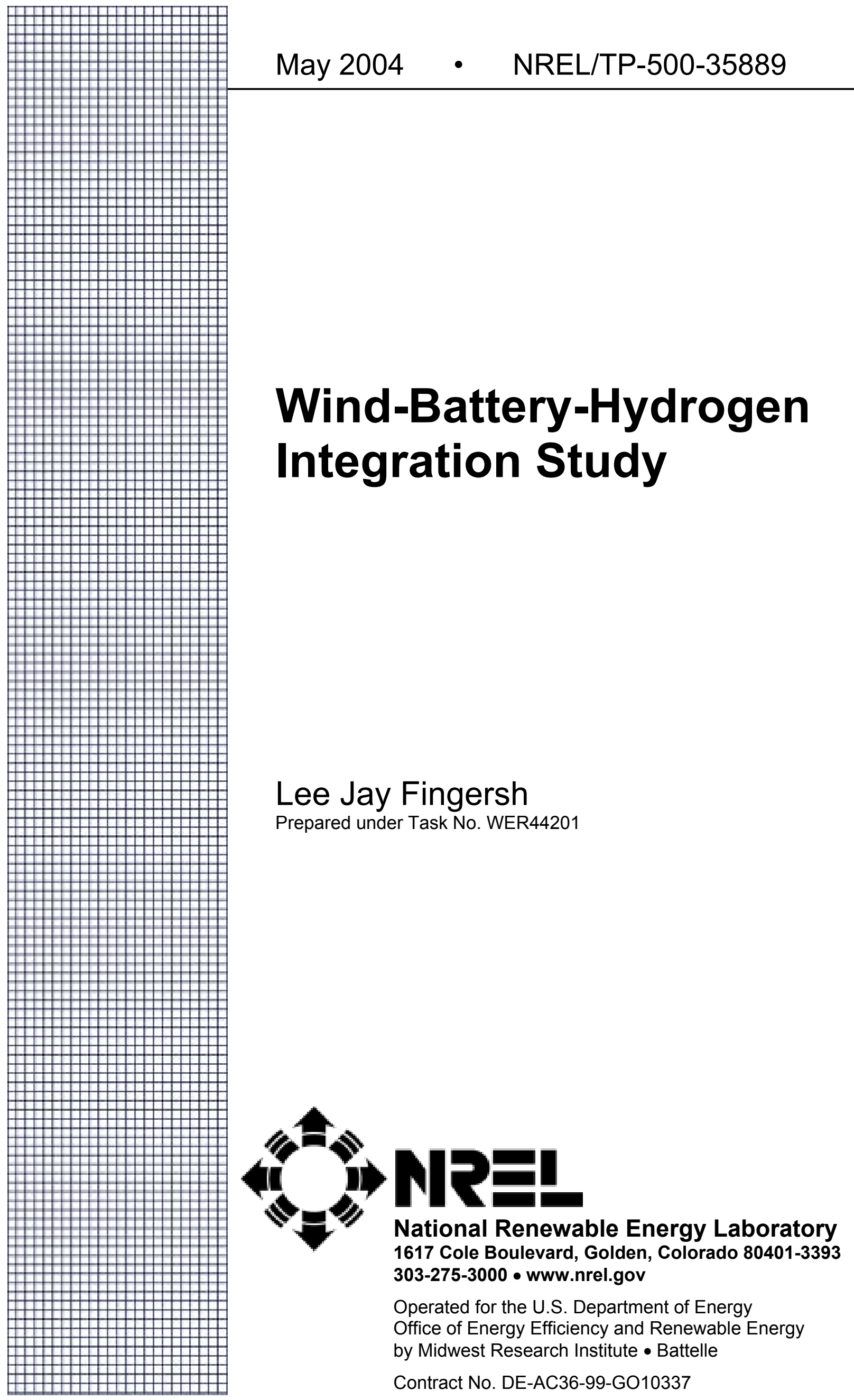




\section{NOTICE}

This report was prepared as an account of work sponsored by an agency of the United States government. Neither the United States government nor any agency thereof, nor any of their employees, makes any warranty, express or implied, or assumes any legal liability or responsibility for the accuracy, completeness, or usefulness of any information, apparatus, product, or process disclosed, or represents that its use would not infringe privately owned rights. Reference herein to any specific commercial product, process, or service by trade name, trademark, manufacturer, or otherwise does not necessarily constitute or imply its endorsement, recommendation, or favoring by the United States government or any agency thereof. The views and opinions of authors expressed herein do not necessarily state or reflect those of the United States government or any agency thereof.

Available electronically at http://www.osti.gov/bridge

Available for a processing fee to U.S. Department of Energy and its contractors, in paper, from:

U.S. Department of Energy

Office of Scientific and Technical Information

P.O. Box 62

Oak Ridge, TN 37831-0062

phone: 865.576 .8401

fax: 865.576 .5728

email: mailto:reports@adonis.osti.gov

Available for sale to the public, in paper, from:

U.S. Department of Commerce

National Technical Information Service

5285 Port Royal Road

Springfield, VA 22161

phone: 800.553 .6847

fax: 703.605.6900

email: orders@ntis.fedworld.gov

online ordering: http://www.ntis.gov/ordering.htm 


\section{Contents}

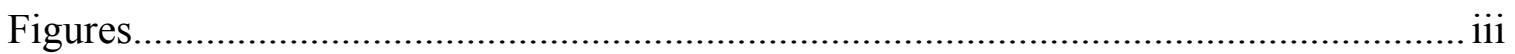

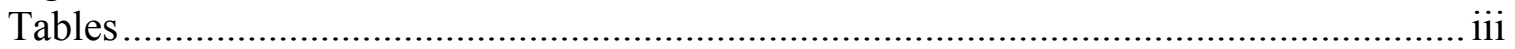

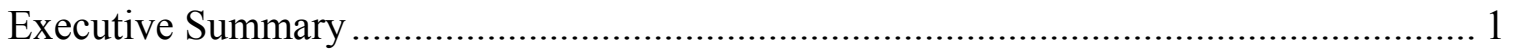

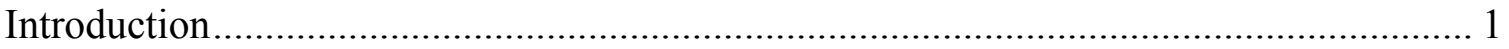

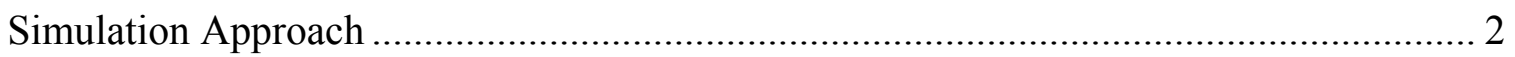

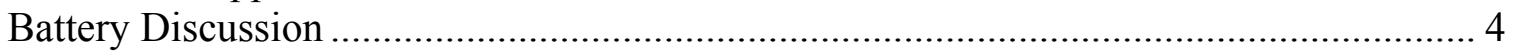

Simulation Results - Wind Firm-Up ........................................................................ 5

Simulation Results - Hydrogen Production................................................................... 8

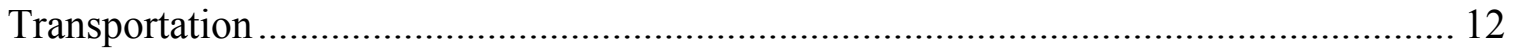

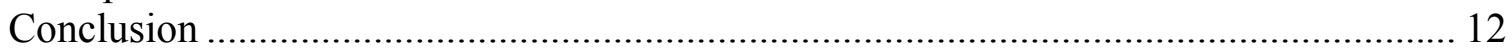

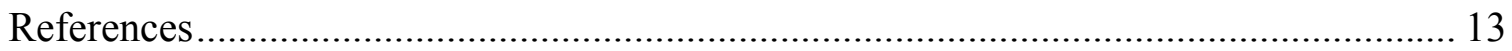

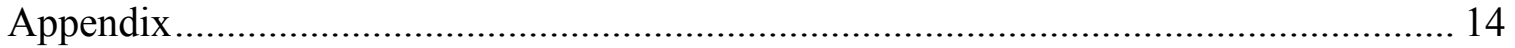

\section{Figures}

Figure 1 - Electrical connections to connect multiple devices to a wind-turbine power

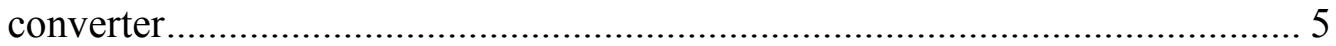

Figure 2 - COE versus battery cost for $50 \%$ capacity reduction at various wind farm costs

Figure 3 - COE versus capacity reduction at various wind energy penetration levels

Figure 4 - Cost of hydrogen versus electrolyzer size for various values of electricity

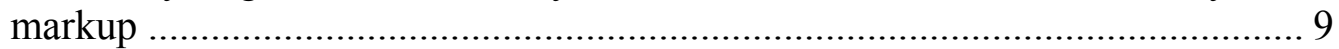

Figure 5 - Cost of hydrogen versus electrolyzer cost for various values of the PTC ....... 10

Figure 6 - Hydrogen production versus electrolyzer size for a $100 \mathrm{MW}$ wind farm........ 11

Figure 7 - Hydrogen transportation costs.................................................................... 12

\section{Tables}

Table 1 - Assumed Costs for Wind Firm-Up................................................................ 5

Table 2 - Assumed Costs for Wind Hydrogen Production .................................................. 8 


\section{Executive Summary}

A study was performed to examine the possibility of using batteries and Hydrogen systems to add dispatchability to wind power. A second study examined the production of hydrogen by wind power for sale into a fuels market. Calendar year 2002 load information from the California ISO was combined with 2002 generated wind power from the Lake Benton wind farm in Minnesota. Control systems were developed and optimized, and grid operation for 2002 was simulated with batteries, electrolyzers, fuel cells or other elements.

Results of the first study indicate that hydrogen systems are not well suited to store grid energy. Since the closed-cycle efficiency of an electrolyzer-fuel cell combination is very low, large amounts of energy are lost in the electricity storage process. Even if the hydrogen systems are brought to zero cost, this energy loss makes the hydrogen system more expensive than a battery. Batteries are very efficient and therefore lose far less energy. This study indicates that energy storage systems can add a substantial amount of dispatchability to wind energy for just $\$ 0.005$ to $\$ 0.020 / \mathrm{kWh}$.

The second study determined that generating hydrogen from wind energy for sale as a fuel works best with an integrated system of wind, batteries, and electrolyzers connected to the grid. Such a system allows for a high electrolyzer capacity factor, which is important because the capital cost of the electrolyzers must be amortized over the amount of hydrogen produced. If more hydrogen is produced per unit of electrolyzer capacity, the net cost of hydrogen is lower. This study indicates that hydrogen can be produced by wind for a cost of $\$ 1.50-\$ 2.25 / \mathrm{kg}$ if the wind energy production tax credit (PTC) is included and $\$ 2.50-\$ 3.25 / \mathrm{kg}$ without the PTC.

\section{Introduction}

Wind energy is currently the most cost-effective non-hydro renewable energy source. However, wind is inherently not dispatchable because wind farm output is a function of wind speed, which the utility cannot control. Although the ability to predict wind farm output from meteorological information is steadily improving, predicting wind farm output is not the same as controlling it.

The ability to control output ("dispatchability" or "firm-up") is desirable because energy users - not the utility - control the load on the grid. However, the power injected into the grid by generation systems must always be equal to the power withdrawn from the grid or the grid frequency and voltage will begin to vary. Since grid frequency and voltage must remain constant, the utility must control the generation system to maintain the generation-load balance.

Control can be added to wind farm power by adding energy storage. In this way, excess energy can be stored and released when needed. Two major questions about such a system are how much energy storage is needed and what type of systems should be employed. A wind farm might be able to create hydrogen through water electrolysis, 
store that hydrogen, and then run it through fuel cells or combustion devices to recover the stored energy. Batteries have also been proposed to store energy. Each technique has advantages and disadvantages that will be examined in this report.

Some researchers have proposed that wind farm energy be used to generate hydrogen for sale into a fuels market. This is very similar to the type of storage mentioned earlier except that the energy will be recovered remotely and not be regenerated onto the grid. Instead, a vehicle will use it at a remote location. This is attractive because that fuel would be supplied by a renewable source, non polluting, domestically generated, and cost competitive not with low-cost grid energy, but with much more expensive transportation fuels. For example, if gasoline is $\$ 1.00 /$ gal (before taxes) and the engine in an automobile is $15 \%$ efficient $^{1}$, the cost of energy at the wheel of the car is $\$ 0.20 / \mathrm{kWh}$. Grid energy in the United States is usually $\$ 0.02-\$ 0.04 / \mathrm{kWh}$. If the wind farm, electrolyzer, fuel transportation, and energy regeneration systems are efficient, wind farm generated hydrogen may be able to compete successfully with current transportation fuels. Since current vehicles are so inefficient (15\%), substantial improvements are possible. Hybrid vehicle technology, better engines and hydrogen as a fuel in combination might double or even triple this efficiency ${ }^{2,3}$. For example, if wind farm generated hydrogen were $\$ 2.00 / \mathrm{kg}$ (1 kg of hydrogen contains roughly the same amount of energy as 1 gallon of gasoline) and vehicle efficiency improved to $30 \%$, the cost of energy at the wheel of the car would be $\$ 0.20 / \mathrm{kWh}$ - comparable to $\$ 1.00 /$ gal gasoline.

\section{Simulation Approach}

Under the wind farm monitoring program at NREL, data were collected on the output of the Lake Benton wind farm in Minnesota. These data are collected at a very high rate but were reduced to an hourly rate for this study. In addition, information about the electricity demand in California was gathered from the California ISO OASIS Web site. These data represent hourly average load demand in the California ISO control area. The basic simulation approach was to add elements such as traditional generation, batteries, hydrogen systems, and dispatchable load (desalination, water heating etc.) to the wind farm data so the aggregate power from all elements is equal to the load at each hourly time step. All these elements (except dispatchable load) would be located at the wind farm. The utility can control dispatchable load, which makes it distinct from normal grid loads. However, it is not considered as energy storage in the model and was not simulated in any cases presented here.

To put a value to the term "dispatchability," it was necessary to define a control objective. The control objective used for these simulations was called "capacity reduction". In a traditional grid, the maximum output power of the entire generation system is usually set based on the hour of the year during which the maximum load will be drawn. In California, this hour is usually in the summer during which air-conditioning loads are high. Ignoring reserves, the total generation capacity must be equal to the maximum load. In the model the control objective was to reduce the required traditional generation capacity by a percentage of the wind farm rated power. For example, if the capacity reduction factor was set to $60 \%$ and the wind farm total installed capacity is 
$100 \mathrm{MW}$, then the traditional generation capacity in the simulation was set to the maximum load minus $60 \mathrm{MW}$. In this way, the wind farm contributes some of its nameplate capacity to firm summer generation capacity by using energy storage elements to ensure that power will be available when the load is high even if the wind isn't blowing.

A wind farm with no energy storage might be able to contribute to firm generation capacity. The approach is to compute the statistical probability that the load can be met with no wind farm (baseline case), with a wind farm, and with additional traditional generation capacity but no wind farm. By adjusting the amount of traditional generation added to the baseline system until the probability in this case is equal to the probability in the case of adding only a wind farm, an equivalent firm capacity is determined. However, determining the equivalent forced outage rate for a wind farm is difficult because it is subject to local meteorology. This leads to difficulty in determining the percentage of the wind farm capacity that should be considered firm (a capacity credit). Even so, this percentage is usually fairly small.

Very simple control systems were developed to maintain generation and load balance at each time step. These control systems basically seek to hold the energy stored in the battery to a constant value by controlling the power of the other controllable elements such as traditional generation, an electrolyzer or some form of dispatchable load. Battery power is then defined as that which is needed to balance all elements with the load. To facilitate easier integration of the control systems, the target value for the battery energy stored was zero; positive numbers represented energy stored in the battery. Negative numbers are allowed because the battery size is not known before the simulation is executed. At the conclusion of the simulation, the minimum value of energy stored in the battery during the year is subtracted from the maximum value. The result is the size of the battery that was required to successfully achieve a proper load balance at each time step.

At the conclusion of the simulation, costs are computed based on the sizes of the elements and their assumed costs. For example, after battery size is computed in kilowatt-hours of energy stored, it is multiplied by the assumed cost per kilowatt-hour of battery energy storage for a final battery cost. After all costs are computed, two cost-ofenergy (COE) numbers are determined - one for the wind farm with no additional elements, the other for the complete system, including a wind farm of the same size and the energy storage elements. The formula used is:

$$
C O E=\frac{\mathrm{FCR} * \mathrm{ICC}+\mathrm{LRC}}{\mathrm{AEP}}+\mathrm{O} \& \mathrm{M}
$$

where FCR is fixed charge rate, ICC is initial capital cost, annual LRC is levelized replacement cost, AEP is annual energy production, and O\&M is operations and maintenance cost in $\$ / \mathrm{kWh}$. Comparing the wind farm only COE to the total COE gives the cost of adding the energy-storage elements and therefore the cost of achieving the control objective. 
Computing the cost of hydrogen production for sale into a fuels market is a bit more complex. Since the wind farm is now selling both electricity and hydrogen, a "with hydrogen" production case and a "without hydrogen, with battery" production case must be compared. All marginal costs are then applied to the Hydrogen production:

$$
\operatorname{Cost}\left(H_{2}\right)=\frac{\text { Marginal cost }}{\text { Hydrogen production }}
$$

To compute the costs of all the elements, all their sizes must be known. As stated above, the simulation computes the battery size. However all other elements (wind farm, capacity reduction, electrolyzer size, traditional generation capacity, etc.) are fixed at the beginning of the simulation. To examine the effect of these parameters on costs, the sizes of these elements were swept over a reasonable range of values and a simulation was run for each case.

\section{Battery Discussion}

Batteries are usually designed for limited use in portable applications. As such, most popular designs are too small and too short lived to be used as grid firm-up devices. For a battery to be successful as an energy storage element in a wind farm, it must be able to store sufficient energy, accept and release energy at a sufficient rate (power), and be low in initial cost and O\&M costs. Since even one cycle per day for 20 years amounts to more than 7,300 cycles, long cycle lifetimes are also required. Several battery technologies have the potential to meet these requirements but here we will focus on two: nickel-hydrogen and vanadium-redox.

Vanadium-redox batteries can be built to have sufficient energy and power, and cycle lifetimes have been reported above 10,000 cycles $^{4}$. The cost of these batteries is reportedly about $\$ 280$ per $\mathrm{kWh}$ of storage ${ }^{4}$.

Nickel-hydrogen batteries work similarly to the popular nickel-metal-hydride batteries except that the hydrogen, instead of being stored in an electrode, is stored externally to the electrochemical portion of the battery. These batteries have been used for many years in space applications where cycle lifetime is crucial. For this application, the hydrogen the battery produces and consumes is assumed to be stored at low pressure in the windturbine tower, which is a potentially very low cost approach (capital cost of $\$ 88 / \mathrm{kg})^{5}$. Projected costs for these batteries are $\$ 70-\$ 280 / \mathrm{kWh}$.

One problem with integrating batteries with wind-turbines is that batteries are inherently DC devices with no means of control. As such, a power converter is required between the battery and the AC utility grid. Power converters are somewhat expensive, so finding a way to avoid having to pay for such a device is desirable. Since many modern windturbines are variable speed, they already contain a power converter. If that power converter has one or more DC links, the batteries might be connectable to a DC link, 
which would avoid the need for a separate power converter. Figure 1 shows how to connect multiple devices to such a power converter.

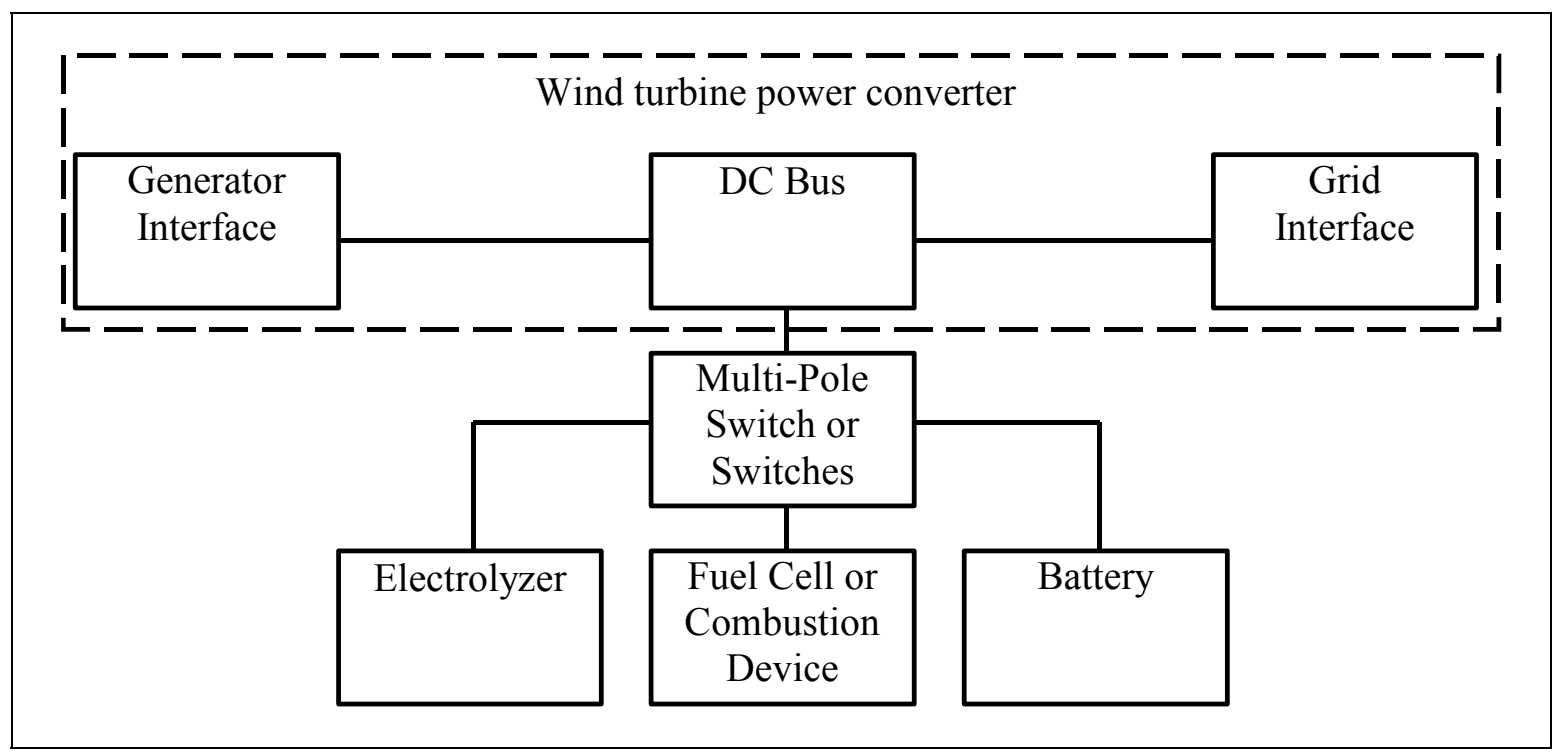

Figure 1 - Electrical connections to connect multiple devices to a wind-turbine power converter

\section{Simulation Results - Wind Firm-Up}

Table 1 lists assumed costs for this part of the study, including the ranges over which parameters were swept. Some parameters were not swept, either because they have little effect on overall costs or because no suitable range data were available.

Table 1 - Assumed Costs for Wind Firm-Up

\begin{tabular}{|c|c|}
\hline Wind farm cost & $\$ 500-\$ 1,000 / \mathrm{kW}$ \\
\hline Battery costs & $\$ 70-\$ 280 / \mathrm{kWh}$ \\
\hline Hydrogen storage costs & $\$ 88 / \mathrm{kg}^{3}$ \\
\hline O\&M cost & $\$ 0.008 / \mathrm{kWh}$ \\
\hline LRC cost & $\$ 15 / \mathrm{kW} /$ year \\
\hline FCR & $10.60 \%$ \\
\hline Production Tax Credit (PTC) & $\$ 0.02$ over wind farm lifetime \\
\hline
\end{tabular}


An example of the simulation results is in Figure 2. The marginal cost of adding substantial firm-up (50\% capacity reduction) is only $\$ 0.005-\$ 0.020 / \mathrm{kWh}$ over the windonly COE of $\$ 0.024 / \mathrm{kWh}$ for a wind farm cost of $\$ 1,000 / \mathrm{kW}$.

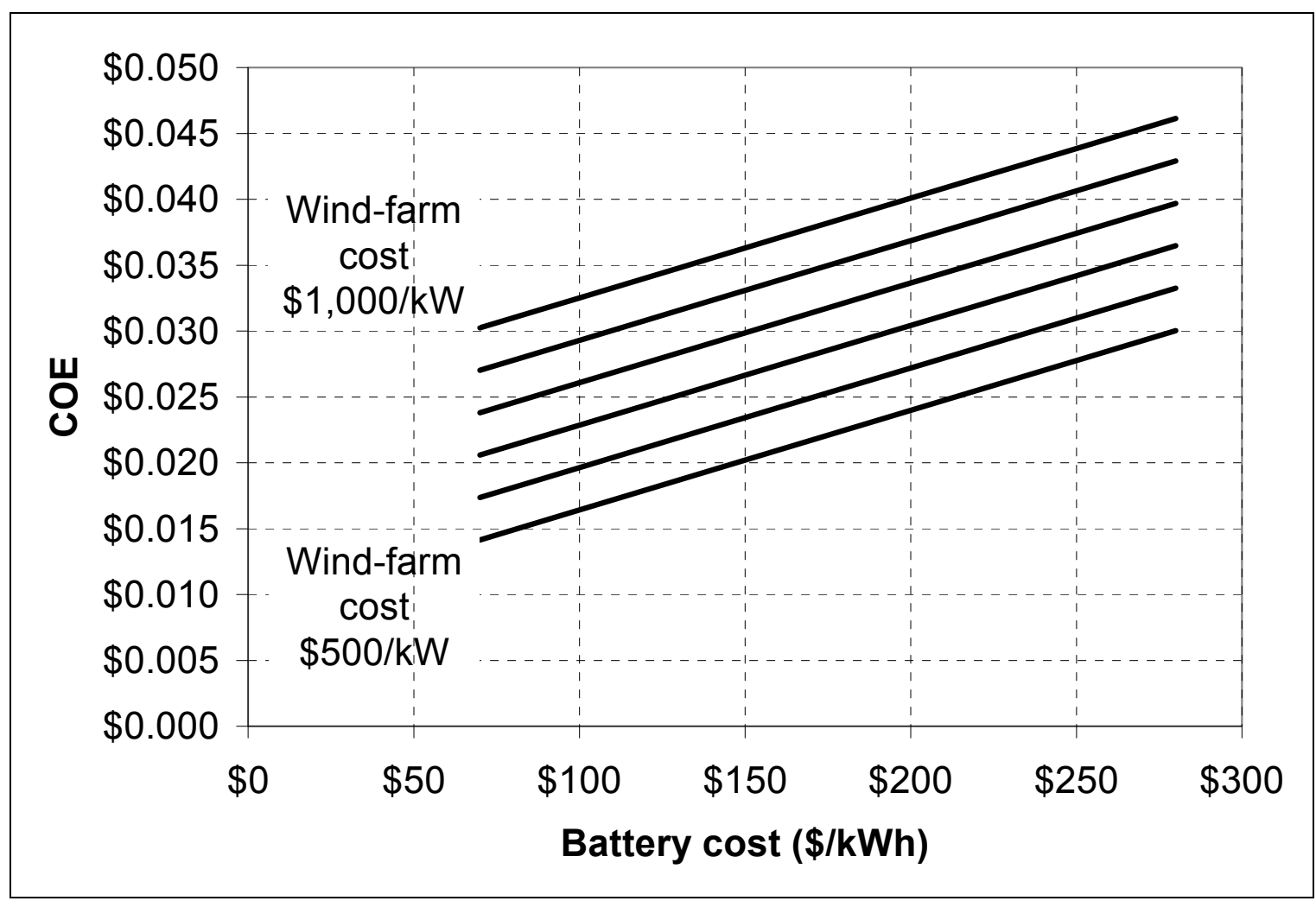

Figure 2 - COE versus battery cost for $50 \%$ capacity reduction at various wind farm costs

An optimizer (Excel Solver) was used to optimize the sizes of the various components and the control parameters of the control systems. The sizes of the electrolyzer and fuel cell were both optimized to zero in favor of the battery. Even though the cost of storing hydrogen is very low $(\$ 88 / \mathrm{kg}$ is less than $\$ 3.00 / \mathrm{kWh})$ the seemingly much more expensive battery $(\$ 70-\$ 280 / \mathrm{kWh})$ is still favored when optimizing COE. The reason for this may have been the cost of the electrolyzer and fuel cell devices. To examine this hypothesis, another simulation was run, this time with the cost of the electrolyzer and fuel cell both set to zero. Even with these costs eliminated, the optimizer favored the battery as a solution for energy storage because of the difference in energy storage efficiencies between the two types of systems. With the battery charge and discharge efficiencies set to $95 \%$ and $90 \%$, respectively, the closed-cycle efficiency of the battery system is $85.5 \%$. With the electrolyzer and fuel cell efficiencies set to $75 \%$ and $50 \%$ (probably optimistic values), the closed cycle efficiency of the hydrogen system is only $37.5 \%$. Therefore, the energy losses in the hydrogen system are too expensive for such a system to be viable against the much more efficient battery system.

Figure 3 shows how the COE varies as the amount of traditional generation capacity reduction is varied. Each point represents the lowest COE value found by the optimizer. 
As the capacity reduction is increased, increasing demands are placed on the wind farm to meet peak loads. As a result, $\mathrm{COE}$ is increased. Also shown is how these costs vary as the energy penetration (energy produced by the wind farm divided by total energy consumed on the grid) is varied. As more wind is brought online, higher demands are placed on the storage systems because the wind's variability becomes a larger fraction of the total grid power. Consequently, costs increase. The baseline costs for all of the cases shown is $\$ 0.0237 / \mathrm{kWh}$ for a wind only (no storage) system. You may note that the curves in Figure 3 asymptote to a value of $\$ 0.0266 / \mathrm{kWh}$, not $\$ 0.0237 / \mathrm{kWh}$. The cause of this discrepancy is a conservative assumption made in the cost analysis. Since the simulation utilizes one hour time steps, setting capacity reduction to $0 \%$ will yield a roughly one hour battery even though, in reality, no demands are being placed on the battery. This is because the battery is always used to make up the difference between the other sources and the load. Since the control systems for all the other sources are causal, they can make bad decisions that will be corrected in the next time step, but in the mean time the battery has to compensate. This leads to batteries that are always about one hour too large and therefore a total COE that is about $\$ 0.0029$ too much. If you would like to eliminate this conservative assumption, subtract this amount from the costs in Figure 3 and in Table A1.

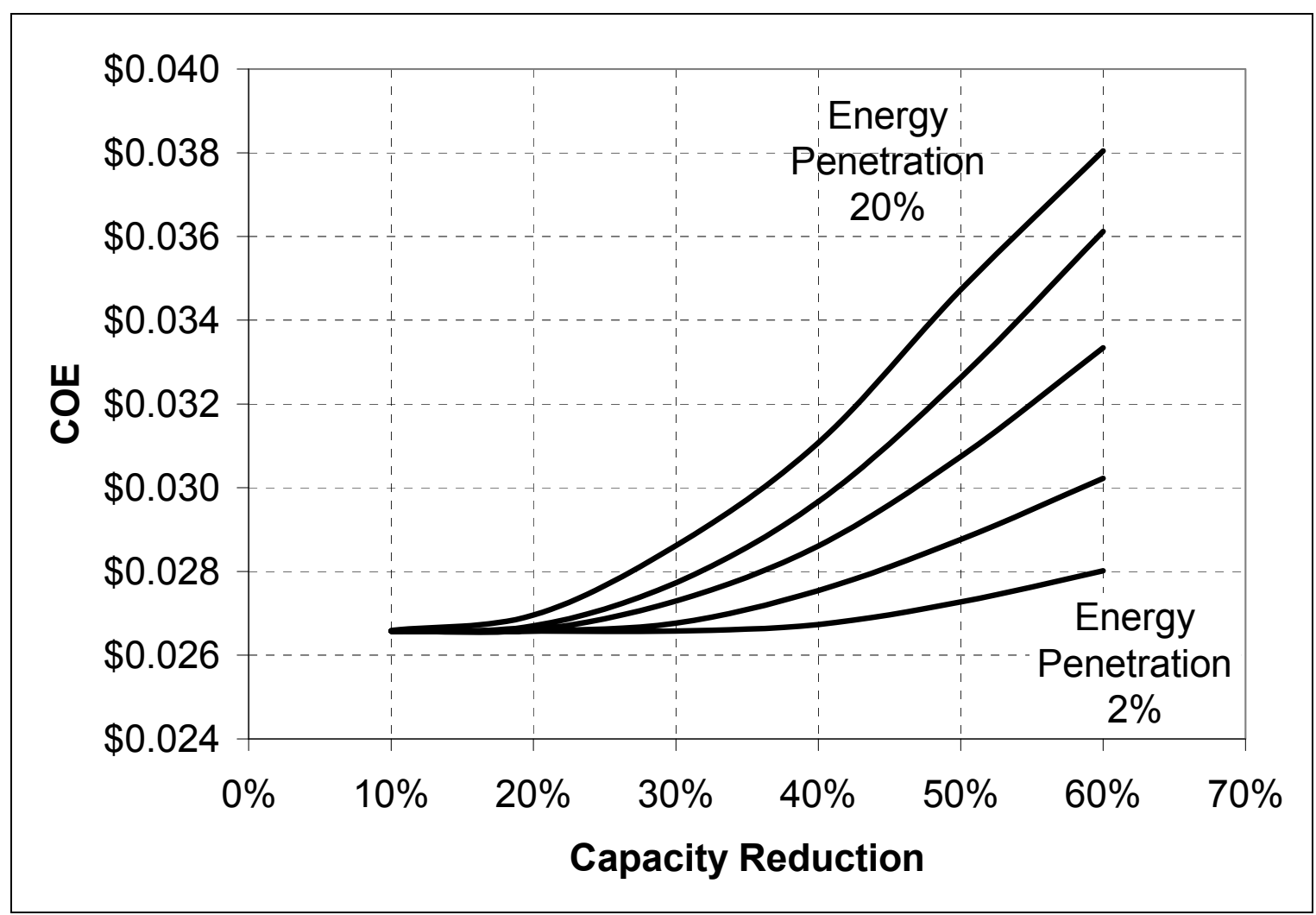

Figure 3 - COE versus capacity reduction at various wind energy penetration levels 


\section{Simulation Results - Hydrogen Production}

For the wind farm to produce net hydrogen for sale, an electrolyzer must be added. Because the optimizer would like to set the size of the electrolyzer to zero, its size had to be fixed so that hydrogen would be produced. However, with the fuel cell size still at zero, all of this hydrogen was exported instead of regenerated into electricity. Nevertheless, with the electrolyzer installed, the control system was able to use it to slightly reduce the size of the battery necessary for wind firm-up by preventing the battery from being over charged during periods of excess energy. It would be used when excess wind was available and the battery was storing high levels of energy. This battery size reduction helped to reduce the cost of the hydrogen produced because the cost of the hydrogen was the marginal cost of the system compared to the wind-battery only system.

Analyzing the cost of hydrogen is complicated because the cost of the electricity absorbed by the electrolyzer must be determined. One is tempted to use the COE from the wind-battery only system as this cost. However, the wind farm operator can no longer sell the electricity that the electrolyzer consumes. This electricity had to be sold at a profit or the operator couldn't stay in business. Therefore the hydrogen production analysis was repeated for three cases: no markup, 10\% markup, and 20\% markup. Cost assumptions for the hydrogen production case are in Table 2.

Table 2 - Assumed Costs for Wind Hydrogen Production

\begin{tabular}{|c|c|}
\hline Wind farm cost & $\$ 1,000 / \mathrm{kW}$ \\
\hline Battery costs & $\$ 70 / \mathrm{kWh}$ \\
\hline Electrolyzer costs & $\$ 200-\$ 1,000 / \mathrm{kW}$ \\
\hline Hydrogen storage costs & $\$ 88 / \mathrm{kg}^{3}$ \\
\hline O\&M cost for wind & $\$ 0.008 / \mathrm{kWh}$ \\
\hline O\&M cost for Hydrogen & $\$ 0.05 / \mathrm{kg}$ \\
\hline LRC cost for wind & $\$ 15 / \mathrm{kW}$ \\
\hline FCR & $10.60 \%$ \\
\hline PTC & $\$ 0.00-\$ 0.02$ over wind farm lifetime \\
\hline
\end{tabular}


Figure 4 shows how the cost of hydrogen varies with electrolyzer size and value of electricity markup. For this case, the electrolyzer cost was set at $\$ 600 / \mathrm{kW}$ and the PTC was set to $\$ 0.020$. The curves are not perfectly smooth because the particular load conditions that govern the size of the components might change as electrolyzer size changes. In other words, a particular day might govern the maximum battery energy stored for one electrolyzer size but with a slightly larger electrolyzer different control parameters may be used that cause another day to govern the battery size. The reason the hydrogen cost increases for increasing electrolyzer size is that a larger electrolyzer doesn't have to work as hard to help the battery. This leads to lower capacity factors for the larger electrolyzers and hence higher hydrogen cost.

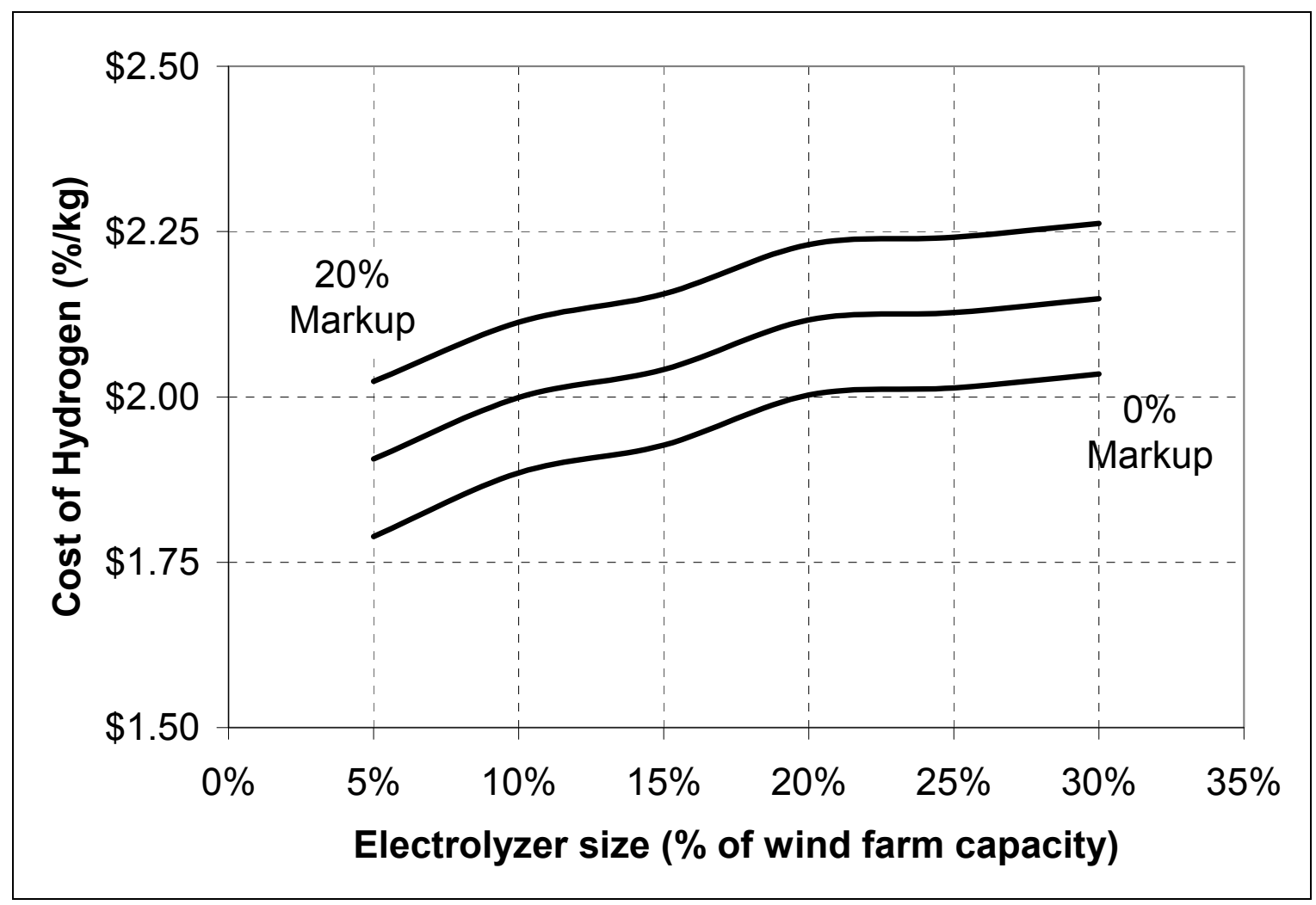

Figure 4 - Cost of hydrogen versus electrolyzer size for various values of electricity markup

A full-sized electrolyzer can be used to convert all the wind-generated electricity to hydrogen. However, this approach reduces the electrolyzer capacity factor to that of the wind farm, which is substantially lower than if a wind-battery-electrolyzer system were used to generate both electricity and hydrogen. This leads to an increase in the cost of hydrogen. 
Figure 5 shows how the cost of hydrogen varies with the electrolyzer cost and the value of the PTC. For this case, the electrolyzer capacity was set to $5 \%$ of the wind farm capacity and the markup was set at $10 \%$.

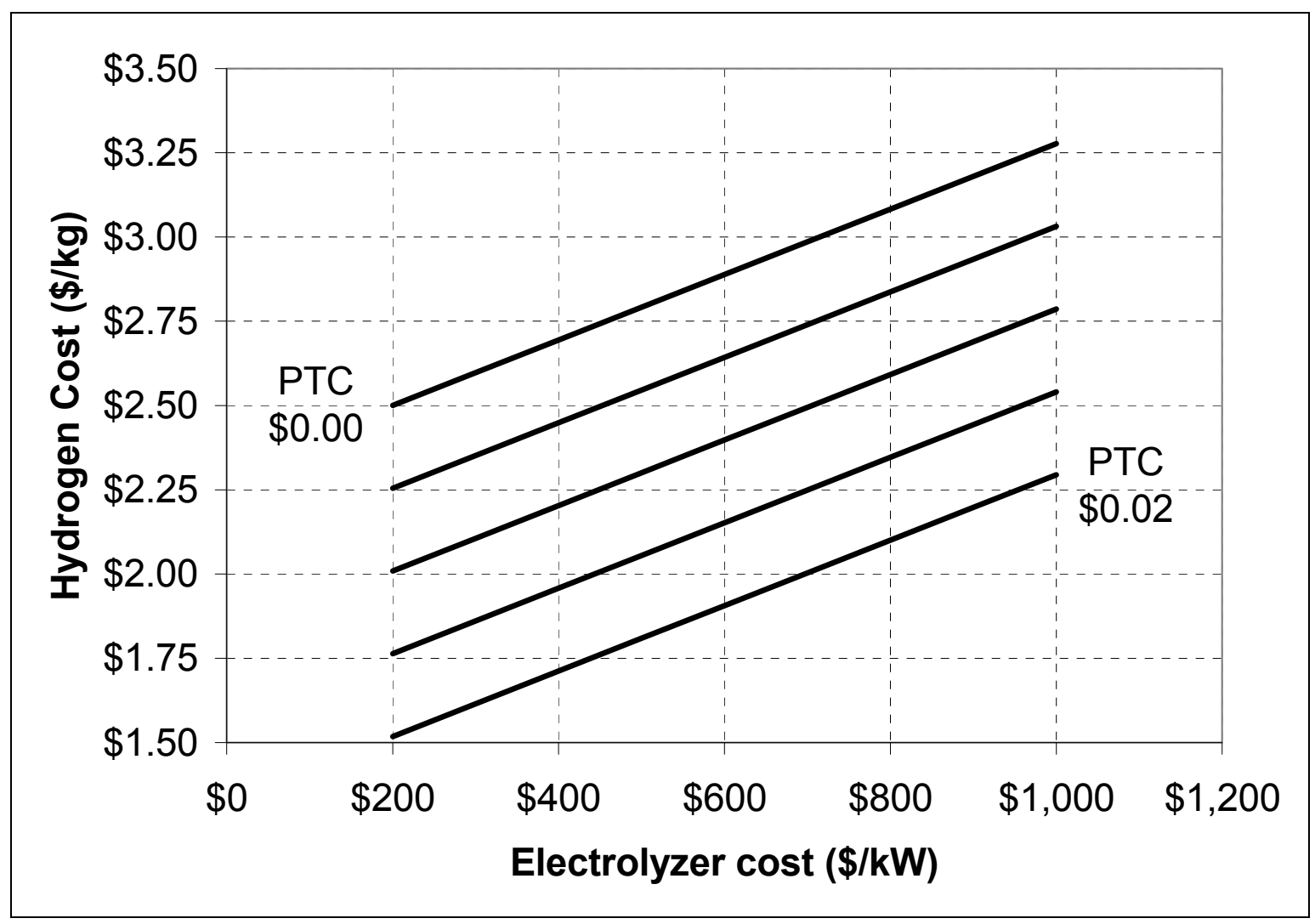

Figure 5 - Cost of hydrogen versus electrolyzer cost for various values of the PTC 
Figure 6 shows how hydrogen production varies with electrolyzer size for a $100 \mathrm{MW}$ wind farm. The slight waviness in this figure is caused by differences in the optimized parameters for each simulation. This is the same as the cause for the waviness in Figure 4. For complete results of the hydrogen production study see the appendix.

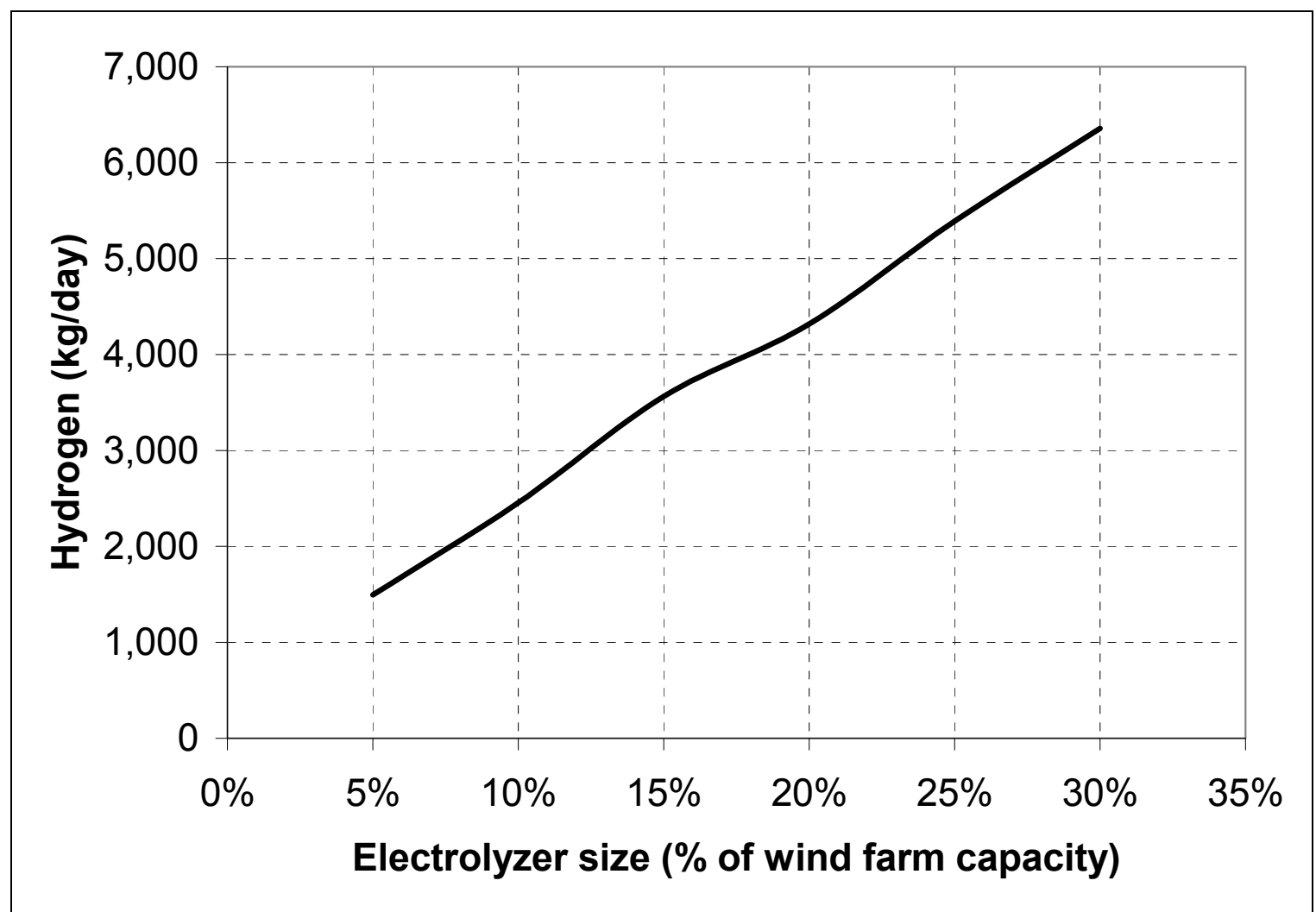

Figure 6 - Hydrogen production versus electrolyzer size for a $100 \mathrm{MW}$ wind farm 


\section{Transportation}

Transportation cost from the wind farm to the point-of-use is an important topic, but is outside the scope of this study. Figure 7 shows the results from another model developed at NREL $^{6}$. This chart clearly shows that production volume is the key to reducing the cost of hydrogen transportation over intermediate distances.

If costs from Figure 4 and Figure 5 are combined with the transportation costs from Figure 7, technology scenarios can be found under which hydrogen production from wind can be at or near the previously mentioned $\$ 2.00 / \mathrm{kg}$ without taxes.

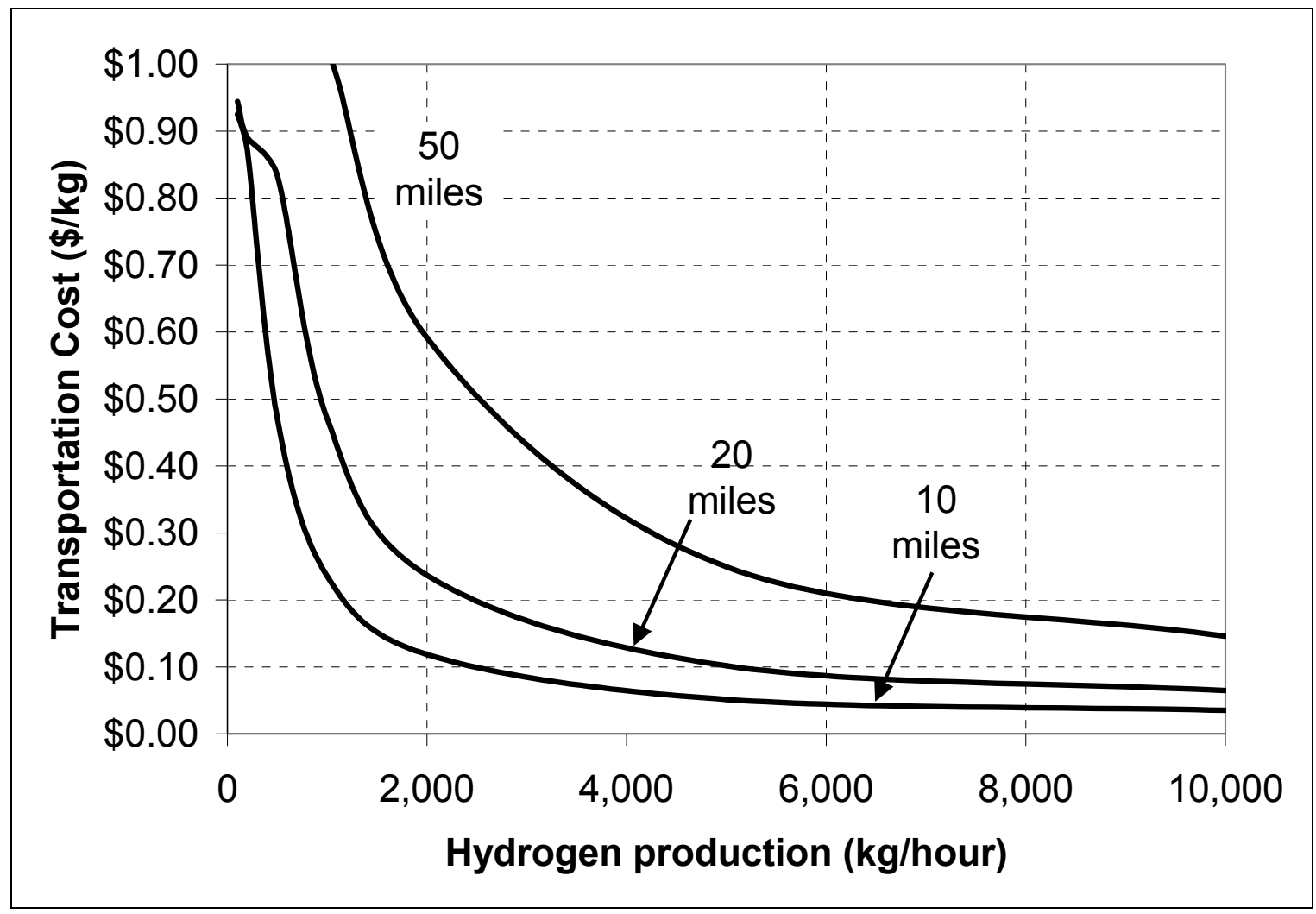

Figure 7 - Hydrogen transportation costs

\section{Conclusion}

This study has shown that, given the assumptions about battery technology (cost, efficiency, and availability), wind power can be firmed up economically. Using batteries for this purpose is better than using hydrogen systems because batteries are much more efficient. If producing hydrogen for fuel is desirable, producing electricity and hydrogen simultaneously is better, because this method reduces the size of the battery and increases the electrolyzer capacity factor, which in turn reduces both the cost of electricity and the cost of hydrogen. Finally, hydrogen as a vehicle fuel can be cost-effectively produced from wind. 


\section{References}

[1] U.S. Department of Energy, Office of Energy Efficiency and Renewable Energy, "Energy Technology and Fuel Economy." http://www.fueleconomy.gov/feg/atv.shtml Accessed 2/17/2004.

[2] Toyota Motor Corporation, "2004 Prius Tech Presentation." http://www.john1701a.com/prius/presentations/2004-prius tech-presentation_49.htm, Slide 49, Accessed 2/20/2004.

[3] The Partnership for a New Generation of Vehicles, PNGV.org, Home Page, Accessed 2/20/2004.

[4] VRB Power Systems, "Executive Summary - VRB Power Systems Inc. and the VRB/ESS.” http://www.vrbpower.com/docs/tpdocs/Executive_Summary.pdf Accessed 2/17/2004.

[5] Kottenstette, R., Cotrell, J. (September 2003). "Hydrogen Storage in Wind Turbine Towers.” NREL/TP-500-34656. Golden, CO: National Renewable Energy Laboratory, $39 \mathrm{pp}$.

[6] Amos, Wade A. (November 1998). "Costs of Storing and Transporting Hydrogen." NREL/TP-570-25106. Golden, CO: National Renewable Energy Laboratory, 216 pp. 


\section{Appendix}

Table A1 - COE for wind farm firm-up - costs from Table 1

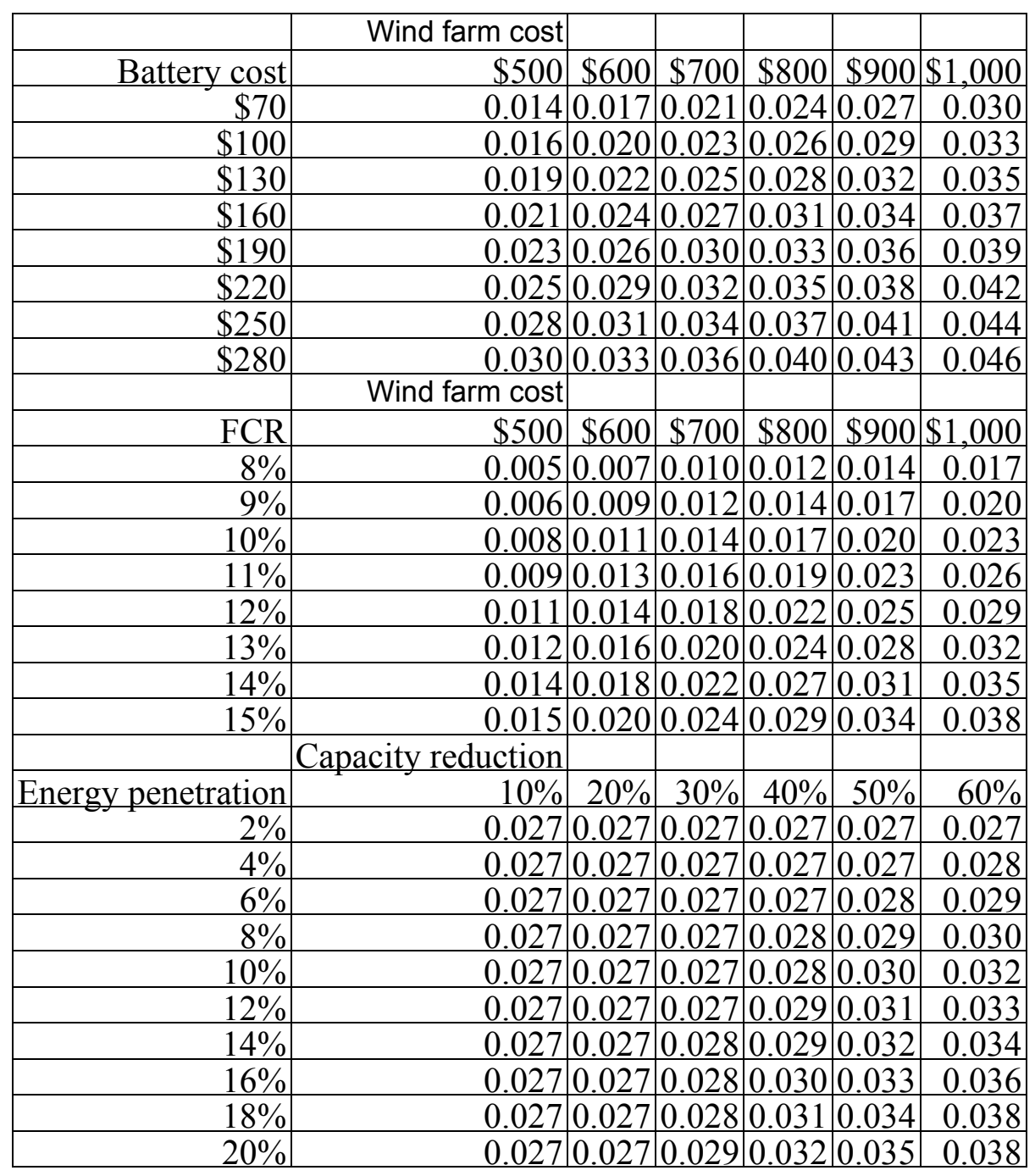


Table A2 - Hydrogen costs $(\mathbf{\$} / \mathbf{k g})$ for $\mathbf{P T C}=\mathbf{\$ 0 . 0 2 0}$

\begin{tabular}{|c|c|c|c|c|c|c|}
\hline \multicolumn{7}{|c|}{ Markup $=0 \%$ Electrolyzer size } \\
\hline Electrolyzer cost & $5 \%$ & $10 \%$ & $15 \%$ & $20 \%$ & $25 \%$ & $30 \%$ \\
\hline$\$ 200$ & 1.400 & 1.412 & 1.438 & 1.465 & 1.475 & 1.486 \\
\hline$\$ 300$ & 1.497 & 1.530 & 1.560 & 1.599 & 1.610 & 1.623 \\
\hline$\$ 400$ & 1.595 & 1.649 & 1.683 & 1.734 & 1.744 & 1.760 \\
\hline$\$ 500$ & 1.692 & 1.767 & 1.805 & 1.868 & 1.879 & 1.898 \\
\hline$\$ 600$ & 1.789 & 1.885 & 1.927 & 2.003 & 2.014 & 2.035 \\
\hline$\$ 700$ & 1.886 & 2.004 & 2.049 & 2.137 & 2.148 & 2.172 \\
\hline$\$ 800$ & 1.983 & 2.122 & 2.172 & 2.272 & 2.283 & 2.309 \\
\hline$\$ 900$ & 2.080 & 2.240 & 2.294 & 2.406 & 2.418 & 2.446 \\
\hline$\$ 1,000$ & 2.177 & 2.358 & 2.416 & 2.541 & 2.552 & 2.583 \\
\hline \multicolumn{7}{|c|}{ Markup $=10 \%$ Electrolyzer size } \\
\hline Electrolyzer cost & $5 \%$ & $10 \%$ & $15 \%$ & $20 \%$ & $25 \%$ & $30 \%$ \\
\hline$\$ 200$ & 1.518 & 1.526 & 1.553 & 1.579 & 1.589 & 1.600 \\
\hline$\$ 300$ & 1.615 & 1.644 & 1.675 & 1.713 & 1.723 & 1.737 \\
\hline$\$ 400$ & 1.712 & 1.762 & 1.797 & 1.848 & 1.858 & 1.874 \\
\hline$\$ 500$ & 1.809 & 1.881 & 1.919 & 1.982 & 1.993 & 2.011 \\
\hline$\$ 600$ & 1.906 & 1.999 & 2.041 & 2.117 & 2.128 & 2.149 \\
\hline$\$ 700$ & 2.003 & 2.117 & 2.164 & 2.251 & 2.262 & 2.286 \\
\hline$\$ 800$ & 2.100 & 2.236 & 2.286 & 2.386 & 2.397 & 2.423 \\
\hline$\$ 900$ & 2.198 & 2.354 & 2.408 & 2.520 & 2.532 & 2.560 \\
\hline$\$ 1,000$ & 2.295 & 2.472 & 2.530 & 2.655 & 2.666 & 2.697 \\
\hline \multicolumn{7}{|c|}{ Markup $=20 \%$ Electrolyzer size } \\
\hline Electrolyzer cost & $5 \%$ & $10 \%$ & $15 \%$ & $20 \%$ & $25 \%$ & $30 \%$ \\
\hline$\$ 200$ & 1.635 & 1.640 & 1.667 & 1.692 & 1.703 & 1.714 \\
\hline$\$ 300$ & 1.732 & 1.758 & 1.789 & 1.827 & 1.837 & 1.851 \\
\hline$\$ 400$ & 1.829 & 1.876 & 1.911 & 1.961 & 1.972 & 1.988 \\
\hline$\$ 500$ & 1.927 & 1.995 & 2.034 & 2.096 & 2.107 & 2.125 \\
\hline$\$ 600$ & 2.024 & 2.113 & 2.156 & 2.230 & 2.241 & 2.262 \\
\hline$\$ 700$ & 2.121 & 2.231 & 2.278 & 2.365 & 2.376 & 2.400 \\
\hline$\$ 800$ & 2.218 & 2.350 & 2.400 & 2.499 & 2.511 & 2.537 \\
\hline$\$ 900$ & 2.315 & 2.468 & 2.523 & 2.634 & 2.646 & 2.674 \\
\hline$\$ 1,000$ & 2.412 & 2.586 & 2.645 & 2.768 & 2.780 & 2.811 \\
\hline
\end{tabular}


Table A3 - Hydrogen costs $(\$ / \mathbf{k g})$ for $\mathbf{P T C}=\$ \mathbf{\$ 0 . 0 1 5}$

\begin{tabular}{|c|c|c|c|c|c|c|}
\hline Markup $=0 \%$ & Electrolyzer size & & & & & \\
\hline Electrolyzer cost & $5 \%$ & $10 \%$ & $15 \%$ & $20 \%$ & $25 \%$ & $30 \%$ \\
\hline$\$ 200$ & 1.622 & 1.634 & 1.660 & 1.687 & 1.697 & 1.708 \\
\hline$\$ 300$ & 1.720 & 1.752 & 1.782 & 1.821 & 1.832 & 1.845 \\
\hline$\$ 400$ & 1.817 & 1.871 & 1.905 & 1.956 & 1.966 & 1.982 \\
\hline$\$ 500$ & 1.914 & 1.989 & 2.027 & 2.090 & 2.101 & 2.120 \\
\hline$\$ 600$ & 2.011 & 2.107 & 2.149 & 2.225 & 2.236 & 2.257 \\
\hline$\$ 700$ & 2.108 & 2.226 & 2.271 & 2.359 & 2.370 & 2.394 \\
\hline$\$ 800$ & 2.205 & 2.344 & 2.394 & 2.494 & 2.505 & 2.531 \\
\hline$\$ 900$ & 2.302 & 2.462 & 2.516 & 2.628 & 2.640 & 2.668 \\
\hline$\$ 1,000$ & 2.399 & 2.580 & 2.638 & 2.763 & 2.774 & 2.805 \\
\hline \multicolumn{7}{|c|}{ Markup $=10 \%$ Electrolyzer size } \\
\hline Electrolyzer cost & $5 \%$ & $10 \%$ & $15 \%$ & $20 \%$ & $25 \%$ & $30 \%$ \\
\hline$\$ 200$ & 1.763 & 1.771 & 1.798 & 1.823 & 1.834 & 1.845 \\
\hline$\$ 300$ & 1.860 & 1.889 & 1.920 & 1.958 & 1.968 & 1.982 \\
\hline$\$ 400$ & 1.958 & 2.007 & 2.042 & 2.092 & 2.103 & 2.119 \\
\hline$\$ 500$ & 2.055 & 2.126 & 2.164 & 2.227 & 2.238 & 2.256 \\
\hline$\$ 600$ & 2.152 & 2.244 & 2.286 & 2.361 & 2.372 & 2.393 \\
\hline$\$ 700$ & 2.249 & 2.362 & 2.409 & 2.496 & 2.507 & 2.530 \\
\hline$\$ 800$ & 2.346 & 2.481 & 2.531 & 2.630 & 2.642 & 2.667 \\
\hline$\$ 900$ & 2.443 & 2.599 & 2.653 & 2.765 & 2.776 & 2.805 \\
\hline$\$ 1,000$ & 2.540 & 2.717 & 2.775 & 2.899 & 2.911 & 2.942 \\
\hline \multicolumn{7}{|c|}{ Markup $=20 \%$ Electrolyzer size } \\
\hline Electrolyzer cost & $5 \%$ & $10 \%$ & $15 \%$ & $20 \%$ & $25 \%$ & $30 \%$ \\
\hline$\$ 200$ & 1.904 & 1.908 & 1.935 & 1.960 & 1.970 & 1.982 \\
\hline$\$ 300$ & 2.001 & 2.026 & 2.057 & 2.095 & 2.105 & 2.119 \\
\hline$\$ 400$ & 2.099 & 2.144 & 2.179 & 2.229 & 2.240 & 2.256 \\
\hline$\$ 500$ & 2.196 & 2.262 & 2.302 & 2.363 & 2.374 & 2.393 \\
\hline$\$ 600$ & 2.293 & 2.381 & 2.424 & 2.498 & 2.509 & 2.530 \\
\hline$\$ 700$ & 2.390 & 2.499 & 2.546 & 2.632 & 2.644 & 2.667 \\
\hline$\$ 800$ & 2.487 & 2.617 & 2.668 & 2.767 & 2.778 & 2.804 \\
\hline$\$ 900$ & 2.584 & 2.736 & 2.791 & 2.901 & 2.913 & 2.941 \\
\hline$\$ 1,000$ & 2.681 & 2.854 & 2.913 & 3.036 & 3.048 & 3.078 \\
\hline
\end{tabular}


Table A4 - Hydrogen costs $(\mathbf{\$} / \mathbf{k g})$ for $\mathrm{PTC}=\mathbf{\$ 0 . 0 1 0}$

\begin{tabular}{|c|c|c|c|c|c|c|}
\hline Markup $=0 \%$ & Electrolyzer size & & & & & \\
\hline Electrolyzer cost & $5 \%$ & $10 \%$ & $15 \%$ & $20 \%$ & $25 \%$ & $30 \%$ \\
\hline$\$ 200$ & 1.844 & 1.856 & 1.882 & 1.909 & 1.919 & 1.930 \\
\hline$\$ 300$ & 1.942 & 1.974 & 2.004 & 2.043 & 2.054 & 2.067 \\
\hline$\$ 400$ & 2.039 & 2.093 & 2.127 & 2.178 & 2.188 & 2.205 \\
\hline$\$ 500$ & 2.136 & 2.211 & 2.249 & 2.312 & 2.323 & 2.342 \\
\hline$\$ 600$ & 2.233 & 2.329 & 2.371 & 2.447 & 2.458 & 2.479 \\
\hline$\$ 700$ & 2.330 & 2.448 & 2.493 & 2.581 & 2.592 & 2.616 \\
\hline$\$ 800$ & 2.427 & 2.566 & 2.616 & 2.716 & 2.727 & 2.753 \\
\hline$\$ 900$ & 2.524 & 2.684 & 2.738 & 2.850 & 2.862 & 2.890 \\
\hline$\$ 1,000$ & 2.621 & 2.803 & 2.860 & 2.985 & 2.997 & 3.027 \\
\hline \multicolumn{7}{|c|}{ Markup $=10 \%$ Electrolyzer size } \\
\hline Electrolyzer cost & $5 \%$ & $10 \%$ & $15 \%$ & $20 \%$ & $25 \%$ & $30 \%$ \\
\hline$\$ 200$ & 2.009 & 2.016 & 2.042 & 2.068 & 2.078 & 2.090 \\
\hline$\$ 300$ & 2.106 & 2.134 & 2.165 & 2.203 & 2.213 & 2.227 \\
\hline$\$ 400$ & 2.203 & 2.252 & 2.287 & 2.337 & 2.348 & 2.364 \\
\hline$\$ 500$ & 2.300 & 2.371 & 2.409 & 2.472 & 2.483 & 2.501 \\
\hline$\$ 600$ & 2.397 & 2.489 & 2.531 & 2.606 & 2.617 & 2.638 \\
\hline$\$ 700$ & 2.495 & 2.607 & 2.654 & 2.741 & 2.752 & 2.775 \\
\hline$\$ 800$ & 2.592 & 2.726 & 2.776 & 2.875 & 2.887 & 2.912 \\
\hline$\$ 900$ & 2.689 & 2.844 & 2.898 & 3.010 & 3.021 & 3.049 \\
\hline$\$ 1,000$ & 2.786 & 2.962 & 3.020 & 3.144 & 3.156 & 3.186 \\
\hline \multicolumn{7}{|c|}{ Markup $=20 \%$ Electrolyzer size } \\
\hline Electrolyzer cost & $5 \%$ & $10 \%$ & $15 \%$ & $20 \%$ & $25 \%$ & $30 \%$ \\
\hline$\$ 200$ & 2.173 & 2.175 & 2.203 & 2.228 & 2.238 & 2.249 \\
\hline$\$ 300$ & 2.271 & 2.294 & 2.325 & 2.362 & 2.373 & 2.386 \\
\hline$\$ 400$ & 2.368 & 2.412 & 2.447 & 2.497 & 2.507 & 2.523 \\
\hline$\$ 500$ & 2.465 & 2.530 & 2.569 & 2.631 & 2.642 & 2.660 \\
\hline$\$ 600$ & 2.562 & 2.649 & 2.692 & 2.766 & 2.777 & 2.798 \\
\hline$\$ 700$ & 2.659 & 2.767 & 2.814 & 2.900 & 2.911 & 2.935 \\
\hline$\$ 800$ & 2.756 & 2.885 & 2.936 & 3.035 & 3.046 & 3.072 \\
\hline$\$ 900$ & 2.853 & 3.003 & 3.058 & 3.169 & 3.181 & 3.209 \\
\hline$\$ 1,000$ & 2.950 & 3.122 & 3.181 & 3.304 & 3.315 & 3.34 \\
\hline
\end{tabular}


Table A5 - Hydrogen costs $(\mathbf{\$} / \mathbf{k g})$ for $\mathrm{PTC}=\mathbf{\$ 0 . 0 0 5}$

\begin{tabular}{|c|c|c|c|c|c|c|}
\hline \multicolumn{7}{|c|}{ Markup $=0 \%$ Electrolyzer size } \\
\hline Electrolyzer cost & $5 \%$ & $10 \%$ & $15 \%$ & $20 \%$ & $25 \%$ & $30 \%$ \\
\hline$\$ 200$ & 2.066 & 2.078 & 2.104 & 2.131 & 2.141 & 2.152 \\
\hline$\$ 300$ & 2.164 & 2.197 & 2.227 & 2.266 & 2.276 & 2.290 \\
\hline$\$ 400$ & 2.261 & 2.315 & 2.349 & 2.400 & 2.410 & 2.427 \\
\hline$\$ 500$ & 2.358 & 2.433 & 2.471 & 2.534 & 2.545 & 2.564 \\
\hline$\$ 600$ & 2.455 & 2.551 & 2.593 & 2.669 & 2.680 & 2.701 \\
\hline$\$ 700$ & 2.552 & 2.670 & 2.715 & 2.803 & 2.815 & 2.838 \\
\hline$\$ 800$ & 2.649 & 2.788 & 2.838 & 2.938 & 2.949 & 2.975 \\
\hline$\$ 900$ & 2.746 & 2.906 & 2.960 & 3.072 & 3.084 & 3.112 \\
\hline$\$ 1,000$ & 2.843 & 3.025 & 3.082 & 3.207 & 3.219 & 3.249 \\
\hline \multicolumn{7}{|c|}{ Markup $=10 \%$ Electrolyzer size } \\
\hline Electrolyzer cost & $5 \%$ & $10 \%$ & $15 \%$ & $20 \%$ & $25 \%$ & $30 \%$ \\
\hline$\$ 200$ & 2.255 & 2.261 & 2.287 & 2.313 & 2.323 & 2.335 \\
\hline$\$ 300$ & 2.352 & 2.379 & 2.410 & 2.448 & 2.458 & 2.472 \\
\hline$\$ 400$ & 2.449 & 2.497 & 2.532 & 2.582 & 2.593 & 2.609 \\
\hline$\$ 500$ & 2.546 & 2.616 & 2.654 & 2.717 & 2.727 & 2.746 \\
\hline$\$ 600$ & 2.643 & 2.734 & 2.776 & 2.851 & 2.862 & 2.883 \\
\hline$\$ 700$ & 2.740 & 2.852 & 2.899 & 2.986 & 2.997 & 3.020 \\
\hline$\$ 800$ & 2.837 & 2.970 & 3.021 & 3.120 & 3.131 & 3.157 \\
\hline$\$ 900$ & 2.934 & 3.089 & 3.143 & 3.255 & 3.266 & 3.294 \\
\hline$\$ 1,000$ & 3.032 & 3.207 & 3.265 & 3.389 & 3.401 & 3.431 \\
\hline \multicolumn{7}{|c|}{ Markup $=20 \%$ Electrolyzer size } \\
\hline Electrolyzer cost & $5 \%$ & $10 \%$ & $15 \%$ & $20 \%$ & $25 \%$ & $30 \%$ \\
\hline$\$ 200$ & 2.443 & 2.443 & 2.471 & 2.495 & 2.505 & 2.517 \\
\hline$\$ 300$ & 2.540 & 2.561 & 2.593 & 2.630 & 2.640 & 2.654 \\
\hline$\$ 400$ & 2.637 & 2.680 & 2.715 & 2.764 & 2.775 & 2.791 \\
\hline$\$ 500$ & 2.734 & 2.798 & 2.837 & 2.899 & 2.910 & 2.928 \\
\hline$\$ 600$ & 2.831 & 2.916 & 2.960 & 3.033 & 3.044 & 3.065 \\
\hline$\$ 700$ & 2.928 & 3.035 & 3.082 & 3.168 & 3.179 & 3.202 \\
\hline$\$ 800$ & 3.025 & 3.153 & 3.204 & 3.302 & 3.314 & 3.339 \\
\hline$\$ 900$ & 3.122 & 3.271 & 3.326 & 3.437 & 3.448 & 3.476 \\
\hline$\$ 1,000$ & 3.220 & 3.390 & 3.449 & 3.571 & 3.583 & 3.613 \\
\hline
\end{tabular}


Table A6 - Hydrogen costs $(\mathbf{\$} / \mathbf{k g})$ for $\mathrm{PTC}=\mathbf{\$ 0 . 0 0 0}$

\begin{tabular}{|c|c|c|c|c|c|c|}
\hline \multicolumn{7}{|c|}{ Markup $=0 \%$ Electrolyzer size } \\
\hline Electrolyzer cost & $5 \%$ & $10 \%$ & $15 \%$ & $20 \%$ & $25 \%$ & $30 \%$ \\
\hline$\$ 200$ & 2.289 & 2.300 & 2.326 & 2.353 & 2.363 & 2.374 \\
\hline$\$ 300$ & 2.386 & 2.419 & 2.449 & 2.488 & 2.498 & 2.512 \\
\hline$\$ 400$ & 2.483 & 2.537 & 2.571 & 2.622 & 2.632 & 2.649 \\
\hline$\$ 500$ & 2.580 & 2.655 & 2.693 & 2.757 & 2.767 & 2.786 \\
\hline$\$ 600$ & 2.677 & 2.773 & 2.815 & 2.891 & 2.902 & 2.923 \\
\hline$\$ 700$ & 2.774 & 2.892 & 2.938 & 3.026 & 3.037 & 3.060 \\
\hline$\$ 800$ & 2.871 & 3.010 & 3.060 & 3.160 & 3.171 & 3.197 \\
\hline$\$ 900$ & 2.968 & 3.128 & 3.182 & 3.294 & 3.306 & 3.334 \\
\hline$\$ 1,000$ & 3.065 & 3.247 & 3.304 & 3.429 & 3.441 & 3.471 \\
\hline \multicolumn{7}{|c|}{ Markup $=10 \%$ Electrolyzer size } \\
\hline Electrolyzer cost & $5 \%$ & $10 \%$ & $15 \%$ & $20 \%$ & $25 \%$ & $30 \%$ \\
\hline$\$ 200$ & 2.500 & 2.506 & 2.532 & 2.558 & 2.568 & 2.579 \\
\hline$\$ 300$ & 2.597 & 2.624 & 2.655 & 2.692 & 2.703 & 2.716 \\
\hline$\$ 400$ & 2.694 & 2.742 & 2.777 & 2.827 & 2.837 & 2.854 \\
\hline$\$ 500$ & 2.792 & 2.860 & 2.899 & 2.961 & 2.972 & 2.991 \\
\hline$\$ 600$ & 2.889 & 2.979 & 3.021 & 3.096 & 3.107 & 3.128 \\
\hline$\$ 700$ & 2.986 & 3.097 & 3.144 & 3.230 & 3.242 & 3.265 \\
\hline$\$ 800$ & 3.083 & 3.215 & 3.266 & 3.365 & 3.376 & 3.402 \\
\hline$\$ 900$ & 3.180 & 3.334 & 3.388 & 3.499 & 3.511 & 3.539 \\
\hline$\$ 1,000$ & 3.277 & 3.452 & 3.510 & 3.634 & 3.646 & 3.676 \\
\hline \multicolumn{7}{|c|}{ Markup $=20 \%$ Electrolyzer size } \\
\hline Electrolyzer cost & $5 \%$ & $10 \%$ & $15 \%$ & $20 \%$ & $25 \%$ & $30 \%$ \\
\hline$\$ 200$ & 2.712 & 2.711 & 2.739 & 2.763 & 2.773 & 2.784 \\
\hline$\$ 300$ & 2.809 & 2.829 & 2.861 & 2.897 & 2.908 & 2.921 \\
\hline$\$ 400$ & 2.906 & 2.948 & 2.983 & 3.032 & 3.042 & 3.058 \\
\hline$\$ 500$ & 3.003 & 3.066 & 3.105 & 3.166 & 3.177 & 3.196 \\
\hline$\$ 600$ & 3.100 & 3.184 & 3.227 & 3.301 & 3.312 & 3.333 \\
\hline$\$ 700$ & 3.197 & 3.302 & 3.350 & 3.435 & 3.446 & 3.470 \\
\hline$\$ 800$ & 3.294 & 3.421 & 3.472 & 3.570 & 3.581 & 3.607 \\
\hline$\$ 900$ & 3.392 & 3.539 & 3.594 & 3.704 & 3.716 & 3.744 \\
\hline$\$ 1,000$ & 3.489 & 3.657 & 3.716 & 3.839 & 3.851 & 3.881 \\
\hline
\end{tabular}




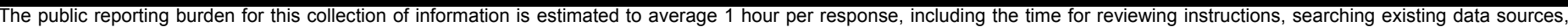

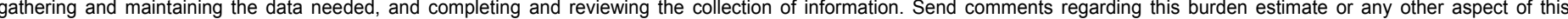

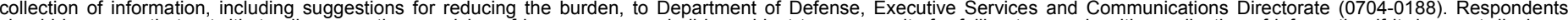

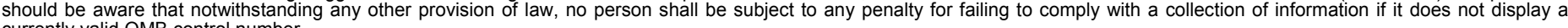
currently valid OMB control number.

PLEASE DO NOT RETURN YOUR FORM TO THE ABOVE ORGANIZATION.

\section{REPORT DATE (DD-MM-YYYY) May 2004}

4. TITLE AND SUBTITLE

Wind-Battery-Hydrogen Integration Study
3. DATES COVERED (From - To)

5a. CONTRACT NUMBER

DE-AC36-99-GO10337

5c. PROGRAM ELEMENT NUMBER

5d. PROJECT NUMBER

NREL/TP-500-35889

5e. TASK NUMBER

WER4.4201

5f. WORK UNIT NUMBER
7. PERFORMING ORGANIZATION NAME(S) AND ADDRESS(ES)

National Renewable Energy Laboratory

1617 Cole Blvd.

Golden, CO 80401-3393
8. PERFORMING ORGANIZATION REPORT NUMBER

NREL/TP-500-35889

9. SPONSORING/MONITORING AGENCY NAME(S) AND ADDRESS(ES)

10. SPONSOR/MONITOR'S ACRONYM(S) NREL

11. SPONSORING/MONITORING AGENCY REPORT NUMBER

\section{DISTRIBUTION AVAILABILITY STATEMENT}

National Technical Information Service

U.S. Department of Commerce

5285 Port Royal Road

Springfield, VA 22161

\section{SUPPLEMENTARY NOTES}

14. ABSTRACT (Maximum 200 Words)

A study was performed to examine the possibility of using batteries and Hydrogen systems to add dispatchability to wind power. A second study examined the production of hydrogen by wind power for sale into a fuels market. Calendar year 2002 load information from the California ISO was combined with 2002 generated wind power from the Lake Benton wind farm in Minnesota. Control systems were developed and optimized, and grid operation for 2002 was simulated with batteries, electrolyzers, fuel cells or other elements. This report presents the results of the two studies.

\section{SUBJECT TERMS}

wind energy; hydrogen; hybrid systems; electrolysis

\begin{tabular}{l}
\hline \multicolumn{3}{|l|}{ 16. SECURITY CLASSIFICATION OF: } \\
\hline \begin{tabular}{l|l|l|} 
a. REPORT & b. ABSTRACT & c. THIS PAGE \\
Unclassified & Unclassified & Unclassified \\
& & \\
\hline
\end{tabular} \\
\hline
\end{tabular}

17. LIMITATION
OF ABSTRACT
UL

18. NUMBER OF PAGES

19a. NAME OF RESPONSIBLE PERSON

19b. TELEPONE NUMBER (Include area code) 